\title{
Acceptance of health-promoting Brassica vegetables: the influence of taste perception, information and attitudes
}

\author{
David N Cox ${ }^{1, *}$, Lauro Melo ${ }^{1}$, Dimitrios Zabaras ${ }^{2}$ and Conor M Delahunty ${ }^{2}$ \\ ${ }^{1}$ CSIRO Food and Nutritional Sciences, Adelaide, South Australia 5000, Australia: ${ }^{2}$ CSIRO Food and \\ Nutritional Sciences, North Ryde, New South Wales, Australia
}

Submitted 20 July 2011: Accepted 17 November 2011: First published online 10 January 2012

\begin{abstract}
Objective: To investigate the relative importance of specific health knowledge and taste on acceptance of Brassica vegetables (broccoli, red and green cabbages, broccolini, cauliflower, Brussels sprouts).

Design: In a sample of adults all reporting medium-high physical activity (as a marker/control of health behaviour) and reporting either low ( $\leq 2$ portions/d) or high ( $\geq 3$ portions/d) vegetable intake, half of those with low vegetable consumption (Li group) and half of those with high vegetable consumption (Hi group) received cancer protection information, while the other half did not (Ln and Hn groups), before hedonic (9-point), perceived taste and flavour impact responses (100 mm scales) to samples of six Brassica vegetables were elicited. Additionally, attitudes towards foods for health, pleasure and reward, sociodemographics, intentions to consume the vegetables in the near future and recall of health information were also measured.

Subjects: Adult males and females ( $n$ 200) aged 18-55 years.

Setting: Central location testing, Adelaide, Australia.

Results: Information groups $\mathrm{Li}$ and Hi reported specific cancer protection information knowledge, in contrast to $\mathrm{Ln}$ and $\mathrm{Hn}$ groups $(P<0 \cdot 000)$. Information independently influenced responses to (the least liked) Brussels sprouts only. Multivariate regression analysis found sensory perception tended to predict liking and intentions to consume Brassica vegetables. For example, broccoli hedonics (adjusted $\left.R^{2}=0.37\right)$ were predicted $(P<0.05)$ by bitterness $(\beta=-0 \cdot 38)$, flavour $(\beta=0 \cdot 31)$, sweetness $(\beta=0 \cdot 17)$ and female gender $(\beta=0 \cdot 19)$ and intentions to consume (adjusted $\left.R^{2}=0 \cdot 20\right)$ were predicted $(P<0 \cdot 05)$ by bitterness $(\beta=-0 \cdot 38)$, flavour $(\beta=0 \cdot 24)$, female gender $(\beta=0 \cdot 20)$ and vegetable intake $(\beta=0 \cdot 14)$.

Conclusions: Addressing taste dimensions (while retaining healthy compounds) may be more important than promoting health information in order to increase the popularity of Brassica vegetables.
\end{abstract}

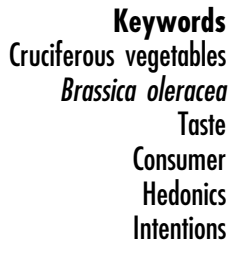

Brassica vegetables (Brassica oleracea) are known to contain compounds that benefit health including organosulfur compounds ${ }^{(1)}$; however, these same compounds can have undesirable sensory characteristics and tend to be disliked ${ }^{(2,3)}$. There is considerable evidence that one of the main determinants of food choice is liking (hedonics $)^{(4)}$. Taste is often reported to be the main driver of liking $^{(5)}$. Innate preferences for sweet taste and innate dislike of bitter taste (fear of alkaloid toxins) and sour taste (aversion towards acids) are determinants of early taste acceptance ${ }^{(2,3,6-8)}$. Change in taste acceptance can be learnt through exposure and/or a wide range of implicit and explicit associative learning through pairings with liked stimuli that can be sensory, post-ingestive effects (e.g. satiation), reward, social acceptance or cognitive (e.g. health information) in nature ${ }^{(9)}$.
One mechanism for increasing the liking of food is the provision of information reporting the health benefits ${ }^{(10)}$. For example, past research has included health information when seeking to increase vegetable (and fruit) consumption $^{(11,12)}$ in clinical trial settings. Other researchers have used health information to effect positive hedonic changes towards novel foods with health benefits ${ }^{(13-17)}$. However, most of these studies used interventions additional to information such as prolonged personal contact, repeated exposure, cookery skills, etc. Nevertheless, Lucknow et al. ${ }^{(13)}$ suggest that health information had an effect upon liking of a probiotic juice additional to exposure. There is also evidence that simple labelling (e.g. soya content) can have a negative impact upon taste perception $^{(18)}$. Furthermore, 'healthy' or 'diet' labelling can have positive effects upon 'appeal' and 'taste' of 
palatable ('hedonic and favourable') desserts but not upon 'utilitarian' savoury dishes ${ }^{(19)}$. It is unknown whether health information alone may influence liking of vegetables thought to be relatively low in palatability.

Furthermore, the source and form of the health information are important ${ }^{(20)}$. Reviews by the authors (D.N.C. and D.Z.) considered a wide range of health information pertaining to vegetables and Brassica vegetables in particular. Weak effects for reduction of cancer risk have recently been reported for vegetables in general $^{(21)}$ although measures of the effects of specific vegetables are lacking. In respect to Brassica vegetables, while epidemiological evidence is lacking (possibly due to a lack of tools to measure Brassica intake), the mechanisms and laboratory evidence are unambiguous ${ }^{(1)}$. In the current study criteria for selection of information were evidence based: lack of ambiguity and a credible and trusted source. As a consequence a recent statement by The Cancer Council Australia was chosen ${ }^{(22)}$. While this pre-dates very recent epidemiological evidence ${ }^{(21)}$, it was a public health message at the time of the study.

Attitudes are known to interact with sensory perception, health attributes and acceptance of foods ${ }^{(23)}$. The Health and Taste Attitude Scale (HTAS) was developed to measure how differing attitudes may influence food choice $^{(24)}$ and validated across selected European cultures $^{(25)}$. In the current study three subscales from the HTAS were hypothesized to be relevant: (i) General (Food for) Health interest, (ii) Food for Pleasure and (iii) Food for Reward. The 'food for health' attitudes subscale taps into health motivations and those scoring highly on this scale were hypothesized to report increased liking and intention to eat Brassica vegetables. Nevertheless, original reports $^{(24)}$ found no negative correlation between 'foods for health' and 'foods for pleasure'. In other words, health and pleasure orientation could occur simultaneously. In contrast, those reporting high scores on the foods for reward' subscale were hypothesized to be oriented more towards hedonic aspects of food choice and therefore negative towards unpalatable vegetables.

Brassica vegetables are not novel and current consumption (exposure and familiarity) is likely to be related to acceptance; hence, current consumption was also considered. In the current study vegetable intake was measured at recruitment screening using a validated measure of portions ${ }^{(26)}$.

The current study is part of a wider project ${ }^{(27)}$ that sought to characterize the taste properties of compounds in Brassica vegetables and the relationships between taste properties and health-promoting properties. In that analysis the chemistry of Brassica vegetables was measured for the purpose of relating acceptance of taste to health-promoting compounds so as to identify compounds that may contribute to sensory acceptance but not to health effects. In the current study perceived basic tastes (sweet, sour, bitter, umami and salt) and overall flavour impact (strength) were measured and hypothesized to be predictors of liking and intentions to consume.

Information that seeks to resolve this dilemma may assist in breeding new cultivars, providing appropriate information to consumers and generally resolve health/palatability issues. Understanding consumers' trade-offs between health benefits and taste and suggesting options for resolving that dilemma will be beneficial to public health nutrition.

The main hypothesis tested was that if specific information, including protecting against cancer, is known (recalled), then such health knowledge may override any taste aversion to Brassica vegetables and increase acceptance (liking and intention to consume).

The overall aim was to determine the trade-off consumers make between the taste and the health properties of Brassica vegetables. In order to achieve this primary aim several steps were undertaken, including measures of: the liking of Brassica vegetables; intentions to consume Brassica vegetables; differences in responses by current consumption of vegetables (high and low groups); the effects on responses of providing health information to half of the participants; the perceived tastes (sweet, salt, sour, bitter, umami) and overall flavour intensity of Brassica vegetables; and attitudes towards foods for health, pleasure and reward.

General health consciousness and behaviours were controlled across all participants by only recruiting people who reported high-moderate physical activity. This was to enable a focus on the influence of specific health information and sensory perception on the (dependent variables) hedonics and intentions to consume selected Brassica vegetables.

\section{Experimental methods}

\section{Vegetables}

Brassica vegetables were selected based upon common (popular) and less common (unpopular) types, guaranteed supply from the same growers over the period of testing and reasonable consumer burden (number of samples tasted in one session). Red cabbage, green cabbage, cauliflower, Brussels sprouts, broccoli and brocollini were selected. Vegetables were purchased on a weekly basis, stored at $4{ }^{\circ} \mathrm{C}$ for a maximum of $5 \mathrm{~d}$, and prepared according to laboratory food handling procedures (CSIRO Risk Assessment Process for Foods for Human Consumption approved). Each vegetable was steamed for $6 \mathrm{~min}$ just prior to serving. Approximately $20 \mathrm{~g}$ servings of each were presented monadically in a randomized balanced design, minimizing first-order and carry-over effects ${ }^{(28)}$.

\section{Information}

A statement from The Cancer Council Australia ${ }^{(22)}$ was simplified and presented verbally and visually to information treatment groups prior to any responses (Fig. 1). 
Vegetables are recommended for their important role as a low-energy-dense source of nutrients (vitamins, minerals, phytochemicals and fibre) and for their contribution weight management, as well as for their probable cancer-protective effect. Ensuring an adequate intake of vegetables is likely to reduce the risk of some cancers.

A recent scientific review suggests cruciferous vegetables (including, broccoli, broccolini, cabbages, cauliflower, Brussels sprouts) may be important because they contain compounds that inhibit carcinogenesis.

Adapted from The Cancer Council Australia 2007. National Cancer Prevention Policy 2007-09. NSW: The Cancer Council Australia.

Fig. 1 The health information provided to the information groups in the present study

All participants were measured for knowledge regardless of their assignment to groups. For ethical reasons the same information was given to non-information groups after the study.

\section{Participants}

An accredited market research company was commissioned to provide participants according to specified inclusion and exclusion criteria (below). Ethical approval was received from CSIRO Human Research Low Risk Review Panel and informed consent was obtained. Central location tests (Adelaide) were undertaken in March 2011. Participants were compensated for their time with a \$AU 30 retail voucher.

\section{Sample size}

Variation in hedonic responses (the main dependent variable) was unknown; however, past experience in similar domains by the senior researchers suggested that forty to fifty participants per group would be sufficient to detect differences at the 5\% level. Hence 200 consumers were sought to attend one central location session of approximately $1 \mathrm{~h}$.

\section{Inclusion and exclusion criteria}

Recruitment was based upon the following inclusion criteria: adult aged 18-55 years (upper limit to control for age-related decline in sensory acuity), 50/50 female/male and reporting moderate-high physical activity. Exclusion criteria were: reporting low physical activity, vegetarians, pregnant women, any allergies to vegetables, residency $<3$ years and not able to understand English.

All potential participants were screened for physical activity and invited to participate if reporting moderate to high physical activity as defined by the validated (short form) International Physical Activity Questionnaire ${ }^{(29,30)}$. The rationale for this was to control for the possible confounder of variation in health-conscious behaviour. Furthermore Wansink ${ }^{(18)}$ suggested that 'health orientated' consumers may be more amenable to 'health' labelling.

\section{Design}

In a two (low vegetable consumption (L) or high vegetable consumption (H)) by two (information (i) or no information (n)) design, we sought fifty participants in each group ( $n$ 200 in total), see Fig. 2.

\begin{tabular}{|c|c|}
\hline $\begin{array}{c}\text { Group } \mathrm{Li} \\
\leq 2 \text { servings vegetables/d } \\
\text { Health information } \\
n 50\end{array}$ & $\begin{array}{c}\text { Group } \mathrm{Hi} \\
\geq 3 \text { servings vegetables/d } \\
\text { Health information } \\
n 50\end{array}$ \\
\hline $\begin{array}{c}\text { Group Ln } \\
\leq 2 \text { servings vegetables/d } \\
\text { No information } \\
n 50\end{array}$ & $\begin{array}{c}\text { Group } \mathrm{Hn} \\
\geq 3 \text { servings vegetables/d } \\
\text { No information } \\
n 50\end{array}$ \\
\hline
\end{tabular}

Fig. 2 Design of the present study $(\mathrm{L}=$ low vegetable consumption; $\mathrm{H}=$ high vegetable consumption; $\mathrm{i}=$ information; $\mathrm{n}=$ no information)

All potential participants were screened and first allocated to one of two groups by vegetable consumption, ensuring that half the numbers of participants were female and half male. Using a validated scale ${ }^{(26)}, \leq 2$ portions/d was considered low and $\geq 3$ portions/d (excluding potatoes and potato products) was considered high. The two consumption groups were then randomly allocated to an information or no-information condition.

\section{Participant tasks}

We first sought affective responses (hedonics) to the vegetable samples; then, in a later task, separately sought analytical responses (taste perception). This was thought to be important because analytical thinking tends to diminish hedonic responses ${ }^{(31,32)}$ and is not typical of real-world behaviour.

Detailed administration was as follows. Health information (Fig. 1) was presented to $50 \%$ of participants; hedonic ratings (9-point labelled scale ${ }^{(33)}$ ) to a randomized presentation of six Brassica vegetable samples were obtained; examples of the five basic tastes were given and taste intensity perception to six vegetable samples by five tastes and flavour ratings were elicited ( $100 \mathrm{~mm}$ line scale) to a second randomized presentation; and, finally, responses were determined to the HTAS health, pleasure and reward subscales ${ }^{(24)}$, intention to consume each vegetable, sociodemographics and supplement use, and two open questions on recall (knowledge) of health information.

\section{Trained panel assessment}

The panel consisted of ten assessors from CSIRO, who had previously been screened for taste and smell acuity and had extensive experience in descriptive sensory analysis across a range of products. All sensory testing took place in the CSIRO Food and Nutritional Sciences, North Ryde sensory laboratory, designed in accordance with International Standards on Sensory Analysis (ISO 6658:198).

The trained panel carried out descriptive analysis to assess the basic taste properties of whole extracts from four Brassica vegetables (broccoli, cauliflower, Brussels sprouts and red cabbage), presented in a randomized order to minimize first-order and carry-over effects, in duplicate in two sessions over $2 \mathrm{~d}$. Further details of the methodology are reported elsewhere ${ }^{(27)}$. 


\section{Analysis}

All analysis was undertaken using the SPSS statistical software package version 17 (SPSS Inc., Chicago, IL, USA) and $P<0.05$ chosen as the level of statistical significance.

The open responses to two questions on health were collapsed and analysed so as to determine if the information groups ( $\mathrm{Hi}$ and $\mathrm{Li}$ ) recalled the cancer protection message in either/or questions to a greater extent than those in the no-information group ( $\mathrm{Hn}$ and $\mathrm{Ln}$ ). Responses were coded (by two researchers for inter-rater reliability) for 'cancer protection', 'general knowledge', 'vague' and 'incorrect/blank' categories. The $\chi^{2}$ test was used to determine if the information groups recalled the cancer protection message statistically significantly more than the no-information groups.

ANOVA was undertaken with hedonic score (for each Brassica vegetable) as a within-subjects factor and information group and reported vegetable intake as between-subjects factors. Similarly ANOVA was undertaken with intention to consume score (for each Brassica vegetable) as a within-subjects factor and information group and reported vegetable intake as between-subjects factors.

Repeated-measures ANOVA with post hoc tests were undertaken between vegetables. Also ANOVA with post boc tests were undertaken within vegetables and within tastes by group. As a validation of the consumers' perception of taste, a trained sensory panel assessed whole extracts of a subset of the six Brassica vegetables for the basic tastes using $100 \mathrm{~mm}$ scales. Reference taste stimuli (e.g. caffeine solutions representing bitterness) were used (but note these were not provided to consumers).

Prior to entry in multivariate models (below) each of the HTAS subscales used was found to have good to acceptable internal consistency; specifically, 'food for health' (Cronbach's $\alpha=0 \cdot 85$ ), 'food for pleasure' (Cronbach's $\alpha=0 \cdot 77$ ) and 'food for reward' (Cronbach's $\alpha=0.57$ ).

In order to capture the wider influences upon hedonics and intentions, a series of hierarchical stepwise multivariate regression analyses was undertaken, placing each independent variable in competition in order to determine significant predictors of the dependent variables: (i) hedonic score and (ii) intention to consume each Brassica vegetable. Independent variables were entered stepwise: in step 1 (sociodemographics) gender, education status and age group; in step 2 (intake and intervention) current vegetable intake (high/low) and information (group); in step 3 (attitudes) 'food for health', 'food for pleasure' and 'food for reward'; and in step 4 (sensory perception specific to each Brassica vegetable) perceived bitter, salt, sweet, umami, sour and overall flavour intensity.

\section{Results}

Two hundred participants (see Table 1) completed all tasks and all responses.
Table 1 Characteristics of participants: Australian adults aged $18-55$ years $(n 200)$

\begin{tabular}{lc}
\hline & Percentage \\
\hline Gender & \\
Male & $49 \cdot 5$ \\
Female & $50 \cdot 5$ \\
Age distribution (years) & \\
$18-30$ & $31 \cdot 0$ \\
$31-40$ & $19 \cdot 5$ \\
$41-50$ & $31 \cdot 0$ \\
$51-55$ & $16 \cdot 5$ \\
Education status (highest) & \\
Some high school & $6 \cdot 0$ \\
High school & $20 \cdot 0$ \\
Technical & $23 \cdot 0$ \\
University & $51 \cdot 0$ \\
Dietary supplement use* & $48 \cdot 0$ \\
\hline
\end{tabular}

*No relationship between dietary supplement use and reported vegetable intake, i.e. there were equal numbers in both groups $\left(\chi^{2} P>0.05\right)$.

Table 2 Overall hedonic ${ }^{\star}$ and intention to consumet mean scores with their standard errors and differences by Brassica vegetable: Australian adults aged $18-55$ years $(n 200)$

\begin{tabular}{|c|c|c|c|c|c|}
\hline \multicolumn{3}{|c|}{ Hedonics } & \multicolumn{3}{|c|}{ Intention } \\
\hline Vegetable & Mean & SE & Vegetable & Mean & SE \\
\hline $\mathrm{Cau}$ & $7 \cdot 43^{a}$ & 0.099 & Broc & $6 \cdot 03^{a}$ & 0.088 \\
\hline Broccoli & $7 \cdot 36^{\mathrm{a}}$ & 0.094 & Cauliflower & $5 \cdot 63^{b}$ & $0 \cdot 111$ \\
\hline Broccolini & $7 \cdot 01^{b}$ & $0 \cdot 106$ & Green cabbage & $5 \cdot 04^{c}$ & 0.124 \\
\hline Green cabbage & $6 \cdot 82^{\mathrm{b}, \mathrm{c}}$ & 0.109 & Broccolini & $4 \cdot 67^{d}$ & 0.129 \\
\hline Red cabbage & $6 \cdot 62^{\mathrm{c}}$ & 0.107 & Red cabbage & $4 \cdot 36^{\mathrm{e}}$ & 0.124 \\
\hline Brussels sprouts & $5 \cdot 52^{d}$ & $0 \cdot 154$ & Brussels sprouts & $3 \cdot 77^{f}$ & 0.149 \\
\hline
\end{tabular}

$\mathrm{a}, \mathrm{b}, \mathrm{c}, \mathrm{d}, \mathrm{e}, \mathrm{f}$ Mean values within a column with unlike subscript letters were significantly different $(P<0.05)$.

${ }^{*} 9$-point scales.

†7-point scales.

Table 2 shows that cauliflower and broccoli were the most liked and Brussels sprouts the least liked overall. Furthermore, Table 2 shows statistically significant differences between each Brassica vegetable for intention to consume in the near future. In general hedonic scores were consistent with intentions; however, participants tended to discriminate more between vegetables for intentions than for hedonics.

\section{The impact of information}

Analyses of the distributions of the four response categories across information and no-information groups revealed that a statistically significantly $(P<0 \cdot 000)$ greater frequency ( $45 \%)$ of participants in the information groups recalled (had knowledge of) 'cancer protection' compared with participants in the no-information groups (only 4\%). Proportions recalling/knowing 'general knowledge' were $47 \%$ for the information groups and $72 \%$ for the no-information groups. Additionally, $22 \%$ in the no-information groups were 'vague or incorrect' in contrast to only 5\% in the information groups. While a larger proportion of participants in the no-information groups recalled the general knowledge, cancer protection was not reported ('unknown', 
not salient) among those not informed by the intervention. Hence this 'new' or salient knowledge among the information groups has some potential to impact upon hedonic and intention to consume responses (below).

Table 3 shows mean scores and their standard errors for hedonics of each Brassica vegetable by consumer group and the effects of consumption level and information.

\section{Univariate analysis}

In ANOVA, information was found to have an independent effect upon liking of (the least liked) Brussels sprouts (Table 3). For three vegetables, information had an effect on liking when interacting with current vegetable intake. In all three examples (green cabbage, cauliflower and broccolini) information and high consumption interacted to increase liking. In other words, participants who reported high consumption (predisposed to eating vegetables) appeared to be influenced by the health information to report an increase in their liking of three Brassica vegetables. However, all effects were small.

Reported general vegetable consumption had an effect upon intentions to consume two vegetables. Information independently had an effect on the intentions to consume (the least liked) Brussels sprouts. Also an interaction with current consumption was found. In other words, when vegetable intake was reported as high, information had a greater effect on responses to Brussels sprouts. For two other vegetables, current reported vegetable consumption had an effect on intentions to consume. However, all effects were weak.

\section{Sensory perception}

No difference in perception of the taste/flavour characteristics of the Brassica vegetables was found by group; hence sensory perception differences across vegetables were tested across the whole sample (Table 4).

Table 3 Mean scores and their standard errors for hedonics (9-point scales) and intentions to consume (7-point scales) Brassica vegetables in the near future by group (vegetable consumption $(\mathrm{L}$, low*; $\mathrm{H}$, hight) $\times$ information (i, information; $\mathrm{n}$, no information)) and effects $(P<0.05)$ of vegetable consumption and information: Australian adults aged 18-55 years ( $n$ 200; fifty in each group)

\begin{tabular}{|c|c|c|c|c|c|c|c|c|c|c|}
\hline & \multicolumn{2}{|c|}{ Li group } & \multicolumn{2}{|c|}{ Ln group } & \multicolumn{2}{|c|}{ Hi group } & \multicolumn{2}{|c|}{ Hn group } & \multirow[b]{2}{*}{ Effects } & \multirow[b]{2}{*}{$P$} \\
\hline & Mean & SE & Mean & SE & Mean & $\mathrm{SE}$ & Mean & SE & & \\
\hline \multicolumn{11}{|l|}{ Hedonic scores } \\
\hline Green cabbage & $6 \cdot 52$ & $0 \cdot 188$ & $6 \cdot 82$ & 0.250 & $7 \cdot 30$ & 0.203 & $6 \cdot 64$ & $0 \cdot 219$ & Consumption $\times$ Information & 0.028 \\
\hline Cauliflower & $7 \cdot 28$ & $0 \cdot 220$ & $7 \cdot 38$ & $0 \cdot 171$ & $7 \cdot 88$ & $0 \cdot 153$ & $7 \cdot 16$ & $0 \cdot 227$ & Consumption $\times$ Information & 0.037 \\
\hline Red cabbage & $6 \cdot 62$ & $0 \cdot 183$ & $6 \cdot 46$ & $0 \cdot 220$ & $6 \cdot 80$ & $0 \cdot 219$ & $6 \cdot 60$ & 0.236 & - & \\
\hline Broccoli & $7 \cdot 20$ & $0 \cdot 190$ & $7 \cdot 24$ & $0 \cdot 195$ & $7 \cdot 76$ & $0 \cdot 133$ & $7 \cdot 24$ & $0 \cdot 219$ & - & \\
\hline Brussels sprouts & $5 \cdot 38$ & $0 \cdot 274$ & $4 \cdot 90$ & $0 \cdot 346$ & $6 \cdot 30$ & $0 \cdot 279$ & $5 \cdot 48$ & 0.303 & $\begin{array}{l}\text { Consumption } \\
\text { Information }\end{array}$ & $\begin{array}{l}0.014 \\
0.032\end{array}$ \\
\hline $\begin{array}{l}\text { Broccolini } \\
\text { Intention scores }\end{array}$ & $6 \cdot 74$ & $0 \cdot 226$ & $7 \cdot 00$ & $0 \cdot 225$ & $7 \cdot 50$ & $0 \cdot 141$ & $6 \cdot 82$ & $0 \cdot 230$ & Consumption $\times$ Information & 0.026 \\
\hline Green cabbage & $4 \cdot 76$ & $0 \cdot 245$ & $4 \cdot 78$ & $0 \cdot 276$ & $5 \cdot 72$ & $0 \cdot 202$ & $4 \cdot 90$ & 0.245 & Consumption & 0.028 \\
\hline Cauliflower & $5 \cdot 64$ & $0 \cdot 219$ & $5 \cdot 42$ & $0 \cdot 260$ & $5 \cdot 86$ & 0.204 & $5 \cdot 60$ & $0 \cdot 198$ & - & \\
\hline Red cabbage & $4 \cdot 36$ & 0.242 & $4 \cdot 16$ & 0.289 & $4 \cdot 64$ & 0.239 & $4 \cdot 28$ & 0.221 & - & \\
\hline Broccoli & $5 \cdot 76$ & $0 \cdot 199$ & $5 \cdot 90$ & $0 \cdot 192$ & $6 \cdot 26$ & $0 \cdot 159$ & $6 \cdot 18$ & $0 \cdot 142$ & Consumption & 0.027 \\
\hline Brussels sprouts & $3 \cdot 68$ & $0 \cdot 285$ & $3 \cdot 60$ & $0 \cdot 323$ & $4 \cdot 56$ & 0.289 & $3 \cdot 24$ & $0 \cdot 272$ & $\begin{array}{l}\text { Information } \\
\text { Consumption } \times \text { Information }\end{array}$ & $\begin{array}{l}0.018 \\
0.035\end{array}$ \\
\hline Broccolini & $4 \cdot 42$ & 0.267 & $4 \cdot 58$ & $0 \cdot 291$ & $5 \cdot 04$ & 0.237 & $4 \cdot 66$ & 0.231 & - & \\
\hline
\end{tabular}

${ }^{*}$ Low $=\leq 2$ portions/d (excluding potatoes and potato products).

+ High $=\geq 3$ portions/d (excluding potatoes and potato products).

Table 4 Brassica vegetables by perceived taste and flavour (mean scores with their standard errors) and tests across vegetable scores $(100 \mathrm{~mm}$ scale): Australian adults aged $18-55$ years $(n 200)$

\begin{tabular}{|c|c|c|c|c|c|c|c|c|c|c|c|c|c|}
\hline & Mean & SE & Mean & $\mathrm{SE}$ & Mean & SE & Mean & SE & Mean & SE & Mean & SE & $P$ value \\
\hline \multirow[t]{2}{*}{ Sweet $(F=120 \cdot 234)$} & \multicolumn{2}{|c|}{ Green cabbage } & \multicolumn{2}{|c|}{ Cauliflower } & \multicolumn{2}{|c|}{ Red cabbage } & \multicolumn{2}{|c|}{ Broccoli } & \multicolumn{2}{|c|}{ Broccolini } & \multicolumn{2}{|c|}{ Brussels sprouts } & \\
\hline & & $1 \cdot 81$ & $3 \cdot 52^{b}$ & $1 \cdot 77$ & $42 \cdot 93^{b}$ & $1 \cdot 70$ & $29 \cdot 71^{\mathrm{C}}$ & $1 \cdot 62$ & $26 \cdot 07^{d}$ & $1 \cdot 51$ & $16 \cdot 55^{\mathrm{e}}$ & $1 \cdot 21$ & 0.000 \\
\hline \multirow[t]{2}{*}{ Salt $(F=12 \cdot 043)$} & \multicolumn{2}{|c|}{ Broccoli } & \multicolumn{2}{|c|}{ Broccolini } & \multicolumn{2}{|c|}{ Brussels sprouts } & \multicolumn{2}{|c|}{ Cauliflower } & \multicolumn{2}{|c|}{ Green cabbage } & \multicolumn{2}{|c|}{ Red cabbage } & \\
\hline & $22 \cdot 91^{\mathrm{a}}$ & $1 \cdot 51$ & $1 \cdot 86^{\mathrm{a}}$ & $1 \cdot 42$ & $21 \cdot 57^{\mathrm{a}, \mathrm{b}}$ & $1 \cdot 46$ & $19 \cdot 40^{b}$ & $1 \cdot 27$ & $16 \cdot 50^{\mathrm{C}}$ & $1 \cdot 23$ & $15 \cdot 81^{\mathrm{c}}$ & $1 \cdot 15$ & 0.000 \\
\hline Sour $(F=28 \cdot 630)$ & $\begin{array}{l}\text { Brussel } \\
28 \cdot 34^{a}\end{array}$ & $\begin{array}{c}\text { prouts } \\
1.83\end{array}$ & $\begin{array}{l}\text { Brocc } \\
21 \cdot 37^{\text {b }}\end{array}$ & $\begin{array}{l}\text { ini } \\
1 \cdot 43\end{array}$ & $\begin{array}{l}\text { Red cal } \\
16 \cdot 34^{\mathrm{C}}\end{array}$ & $\begin{array}{l}\text { age } \\
1 \cdot 28\end{array}$ & $\begin{array}{l}\text { Broc } \\
16 \cdot 08^{\mathrm{C}}\end{array}$ & $1 \cdot 29$ & $\begin{array}{l}\text { Green ce } \\
14 \cdot 49^{\mathrm{c}, \mathrm{d}}\end{array}$ & $\begin{array}{r}\text { bage } \\
1 \cdot 29\end{array}$ & $\begin{array}{l}\text { Caulif } \\
12 \cdot 30^{\mathrm{d}}\end{array}$ & $\begin{array}{l}\text { Ner } \\
1.05\end{array}$ & 0.000 \\
\hline Bitter $(F=$ & \multicolumn{2}{|c|}{ Brussels sprouts } & \multicolumn{2}{|c|}{ Broccolini } & \multicolumn{2}{|c|}{ Broccoli } & \multicolumn{2}{|c|}{ Red cabbage } & \multicolumn{2}{|c|}{ Cauliflower } & \multicolumn{2}{|c|}{ Green cabbage } & \\
\hline Umami $(F=3 \cdot 832)$ & \multicolumn{2}{|c|}{ Broccoli } & $\begin{array}{c}32 \cdot 52^{b} \\
\text { Broce }\end{array}$ & $\begin{array}{l}1 \cdot 78 \\
\text { ini }\end{array}$ & $\begin{array}{l}22 \cdot 83^{c} \\
\text { Brussels }\end{array}$ & $\begin{array}{r}1 \cdot 45 \\
\text { prouts }\end{array}$ & $\begin{array}{l}19 \cdot 97^{\mathrm{C}} \\
\text { Caulifl }\end{array}$ & $\begin{array}{l}1 \cdot 38 \\
\text { ver }\end{array}$ & $\begin{array}{l}15 \cdot 64^{\mathrm{d}} \\
\text { Red cal }\end{array}$ & $\begin{array}{l}1 \cdot 24 \\
\text { page }\end{array}$ & $\begin{array}{l}14 \cdot 44^{d} \\
\text { Green }\end{array}$ & $\begin{array}{r}1 \cdot 13 \\
\text { bage }\end{array}$ & 0.000 \\
\hline \multirow[t]{2}{*}{ Flavour impact $(F=5 \cdot 819)$} & $\begin{array}{r}37 \cdot 49^{\mathrm{a}} \\
\text { Bro }\end{array}$ & $1 \cdot 87$ & $\begin{array}{l}36 \cdot 43^{a, b} \\
\text { Brussels }\end{array}$ & $\begin{array}{r}1 \cdot 83 \\
\text { prouts }\end{array}$ & $\begin{array}{r}35 \cdot 59^{\mathrm{a}, \mathrm{b}, \mathrm{c}} \\
\text { Caulifl }\end{array}$ & $\begin{array}{l}1 \cdot 83 \\
\text { ver }\end{array}$ & $\begin{array}{l}34 \cdot 24^{b, c, d} \\
\text { Green } c a\end{array}$ & $\begin{array}{l}1 \cdot 79 \\
\text { bage }\end{array}$ & $\begin{array}{r}33 \cdot 09^{\mathrm{c}, \mathrm{d}} \\
\text { Brocc }\end{array}$ & $\begin{array}{l}1 \cdot 71 \\
\text { lini }\end{array}$ & $\begin{array}{l}32 \cdot 17^{\mathrm{d}} \\
\text { Red }\end{array}$ & $\begin{array}{l}1.69 \\
\text { page }\end{array}$ & 0.002 \\
\hline & $55 \cdot 48^{a}$ & $1 \cdot 62$ & $55 \cdot 24^{a}$ & 1.94 & $53 \cdot 96^{\mathrm{a}, \mathrm{b}}$ & 1.52 & $52 \cdot 17^{\mathrm{a}, \mathrm{b}}$ & 1.59 & $51 \cdot 17^{\mathrm{b}}$ & 1.59 & $46 \cdot 92^{\mathrm{C}}$ & $1 \cdot 51$ & 0.000 \\
\hline
\end{tabular}

a,b,c,d,e Mean values within a row with unlike subscript letters were significantly different $(P<0.05)$. 
Table 5 Trained panel $(n 10)$ sensory ratings of five basic tastes for selected Brassica vegetable whole extracts (100 mm scale) and statistically significant differences $(P<0.05)$ across vegetables

\begin{tabular}{|c|c|c|c|c|c|c|}
\hline & Mean & Mean & Mean & Mean & SED & $P$ value \\
\hline Sweet $(F=23 \cdot 3)$ & $\begin{array}{c}\text { Cauliflower } \\
40 \cdot 5^{\mathrm{a}}\end{array}$ & $\begin{array}{c}\text { Red cabbage } \\
39 \cdot 6^{\mathrm{a}}\end{array}$ & $\begin{array}{c}\text { Broccoli } \\
21 \cdot 9^{\mathrm{b}}\end{array}$ & $\begin{array}{c}\text { Brussels sprouts } \\
24 \cdot 3^{\mathrm{b}}\end{array}$ & $2 \cdot 9$ & $<0.0001$ \\
\hline Salt $(F=6 \cdot 4)$ & Broccoli & Red cabbage & Cauliflower & Brussels sprouts & & \\
\hline $\operatorname{Sour}(F=1 \cdot 4)$ & $\begin{array}{l}42 \cdot 1^{\mathrm{a}} \\
\text { Brussels sprouts }\end{array}$ & $\begin{array}{c}34 \cdot 0^{\mathrm{b}} \\
\text { Broccoli }\end{array}$ & $\begin{array}{l}33 \cdot 1^{\mathrm{b}} \\
\text { Cauliflower }\end{array}$ & $\begin{array}{c}33 \cdot 0^{\mathrm{b}} \\
\text { Red cabbage }\end{array}$ & $2 \cdot 6$ & $<0.001$ \\
\hline & $25 \cdot 5$ & $25 \cdot 5$ & $20 \cdot 3$ & 23.0 & $2 \cdot 9$ & NS \\
\hline Bitter $(F=21 \cdot 3)$ & Brussels sprouts & Red cabbage & Broccoli & Cauliflower & & \\
\hline & $43 \cdot 4^{\mathrm{a}}$ & $30 \cdot 5^{\mathrm{b}}$ & $28 \cdot 6^{b}$ & $18 \cdot 5^{\mathrm{c}}$ & $3 \cdot 2$ & $<0.0001$ \\
\hline Umami $(F=3.9)$ & $\begin{array}{c}\text { Broccoli } \\
41 \cdot 0\end{array}$ & $\begin{array}{c}\text { Cauliflower } \\
36.6\end{array}$ & $\begin{array}{c}\text { Red cabbage } \\
36 \cdot 2\end{array}$ & $\begin{array}{c}\text { Brussels sprouts } \\
31.9\end{array}$ & $2 \cdot 7$ & NS \\
\hline
\end{tabular}

${ }^{\mathrm{a}, \mathrm{b}, \mathrm{c}}$ Mean values within a row with unlike subscript letters were significantly different $(P<0.05)$.

Further analysis investigated whether within a vegetable and within a taste there were differences across groups. All ratings were found to be not statistically significantly different $(P>0 \cdot 05)$. Hence current general vegetable consumption and health information knowledge would appear to be not directly associated with the perceptions of taste and flavour of selected Brassica vegetables. However, individuals may differ in their perceptions of the tastes/ flavour so further analysis was undertaken (below).

The validity of the consumer perceptions of tastes was supported by a trained sensory panel's descriptive sensory assessment scores. Overall there was generally good agreement (rank order and significant differences), particularly for sweetness, bitterness and salt, between the results from the descriptive assessment of the taste attributes of whole extracts of a subset of the Brassica vegetables using trained panellists (see Table 5) and those obtained from the consumer test.

\section{Multivariate models}

More comprehensive analysis of data was undertaken to address the main research question by placing a wide range of measures (see Experimental methods above) as independent variables (predictors) in competition with one another to determine significant predictors of the dependent variables, hedonics and intentions to consume.

With minimal evidence for differences between groups, the sample was analysed as a whole ( $n$ 200). Multivariate regression analysis included a wide range of measured variables, including sociodemographics, information and consumption (as suggested by the univariate analysis), sensory perception and attitudes as independent variables, entered into models in competition with one another, with individual's scores for hedonics (9-point scale) and intentions to consume (7-point scale) selected Brassica vegetables as the dependent variables (Table 6).

Table 6 shows that sensory perception dominated, with attitudes contributing to a lesser degree to the acceptance of Brassica vegetables. Not surprisingly, being female and of older age were positive predictors of acceptance of some Brassica vegetables. Notably 'food for pleasure' and 'food for health' were only minor positive predictors for two (different) vegetables. In contrast, 'food for reward' was a negative predictor in only one case.

Information had only a small effect upon intentions to consume one vegetable, Brussels sprouts (consistent with univariate analysis), but may be important for this particular vegetable. Additionally this suggests that when a food is unpopular, information has the potential to influence responses positively.

In summary, the multivariate models identified where variation in consumer characteristics and perceptions was associated with the liking and intentions to consume Brassica vegetables. These analyses suggest where interventions may effect successful change.

\section{Discussion}

The results do not support the main hypothesis. Specific health information, including protecting against cancer, did not override taste aversion to Brassica vegetables and increase acceptance (liking and intention to consume).

Both the hedonic and intentions data reflected the current market popularity of broccoli and cauliflower ${ }^{(34)}$, suggesting validity of our measures.

The results suggest that the health information had potential to have impact. Both the information and the no-information groups were asked what they thought were the health benefits of vegetables and Brassica vegetables in particular. Information pertaining to the cancer protection afforded by Brassica vegetable consumption was not generally recalled ('known') by those not immediately informed (no-information groups) during the study. A recent review of the theoretical basis of information processing pertaining to food labelling ${ }^{(35)}$ suggests that the information presented in the current study possessed the novelty (unexpectedness) and structure (salience) necessary for appropriate information processing. Almost all of the intervention group (95\%) could recall or state either specific or general health benefits of vegetables in contrast to participants in the no-information groups, of whom almost one in four could not state any 'correct' knowledge. Furthermore, the majority of participants in the 
Table 6 Multivariate predictors of hedonics and intentions to consume Brassica vegetables: Australian adults aged 18-55 years ( $n$ 200)

\begin{tabular}{|c|c|c|c|c|c|c|c|c|}
\hline & \multicolumn{4}{|c|}{ Hedonics } & \multicolumn{4}{|c|}{ Intention } \\
\hline & $\beta$ & $B$ & SE & $P$ & $\beta$ & $B$ & SE & $P$ \\
\hline Broccoli & \multicolumn{4}{|c|}{ (adjusted $R^{2}=0.37$ ) } & \multicolumn{4}{|c|}{ (adjusted $R^{2}=0 \cdot 20$ ) } \\
\hline Constant & & $5 \cdot 830$ & 0.312 & 0.000 & & $4 \cdot 451$ & 0.409 & 0.000 \\
\hline Perceived bitterness & $-0 \cdot 38$ & -0.025 & 0.004 & 0.000 & $-0 \cdot 38$ & -0.018 & 0.004 & 0.000 \\
\hline Flavour impact & $0 \cdot 31$ & 0.018 & 0.004 & 0.000 & 0.24 & $0 \cdot 013$ & 0.004 & 0.000 \\
\hline Gender (female) & $0 \cdot 19$ & 0.511 & $0 \cdot 156$ & 0.001 & $0 \cdot 20$ & 0.501 & $0 \cdot 164$ & 0.003 \\
\hline Perceived sweetness & $0 \cdot 17$ & 0.010 & 0.004 & 0.007 & - & - & - & - \\
\hline Vegetable intake & - & - & - & - & $0 \cdot 14$ & $0 \cdot 331$ & $0 \cdot 163$ & 0.044 \\
\hline Green cabbage & \multicolumn{4}{|c|}{ (adjusted $R^{2}=0 \cdot 27$ ) } & \multicolumn{4}{|c|}{ (adjusted $R^{2}=0.19$ ) } \\
\hline Constant & & $5 \cdot 510$ & 0.312 & 0.000 & & 3.569 & 0.385 & 0.000 \\
\hline Perceived sourness & -0.35 & -0.029 & 0.005 & 0.000 & $-0 \cdot 17$ & -0.017 & 0.007 & 0.000 \\
\hline Flavour impact & $0 \cdot 31$ & 0.020 & 0.004 & 0.000 & 0.24 & 0.019 & 0.005 & 0.000 \\
\hline Food for pleasure & $0 \cdot 15$ & $0 \cdot 250$ & $0 \cdot 100$ & 0.013 & $0 \cdot 20$ & 0.365 & $0 \cdot 130$ & 0.005 \\
\hline Age & $0 \cdot 14$ & $0 \cdot 192$ & 0.088 & 0.030 & $0 \cdot 14$ & $0 \cdot 226$ & $0 \cdot 111$ & 0.043 \\
\hline Food for reward & - & - & - & - & $-0 \cdot 19$ & -0.277 & $0 \cdot 103$ & 0.008 \\
\hline Cauliflower & \multicolumn{4}{|c|}{ (adjusted $R^{2}=0.24$ ) } & \multicolumn{4}{|c|}{ (adjusted $R^{2}=0.13$ ) } \\
\hline Constant & & $6 \cdot 399$ & 0.251 & 0.000 & & $3 \cdot 786$ & 0.406 & 0.000 \\
\hline Perceived bitterness & -0.32 & -0.026 & 0.005 & 0.000 & - & - & - & - \\
\hline Flavour impact & 0.40 & 0.026 & 0.004 & 0.000 & $0 \cdot 24$ & 0.017 & 0.005 & 0.001 \\
\hline Gender (female) & - & - & - & - & $0 \cdot 21$ & $0 \cdot 651$ & $0 \cdot 217$ & 0.003 \\
\hline Food for reward & - & - & - & - & $-0 \cdot 16$ & -0.203 & 0.089 & 0.023 \\
\hline Red cabbage & \multicolumn{4}{|c|}{ (adjusted $R^{2}=0.26$ ) } & \multicolumn{4}{|c|}{ (adjusted $R^{2}=0.11$ ) } \\
\hline Constant & & $5 \cdot 026$ & 0.372 & 0.000 & & $2 \cdot 97$ & 0.307 & 0.000 \\
\hline Flavour impact & 0.42 & 0.029 & 0.004 & 0.000 & $0 \cdot 27$ & 0.023 & 0.006 & 0.000 \\
\hline Perceived sourness & $-0 \cdot 30$ & -0.024 & 0.005 & 0.000 & - & - & - & - \\
\hline Gender (female) & $0 \cdot 14$ & 0.422 & $0 \cdot 185$ & 0.024 & - & - & - & - \\
\hline Food for health & - & - & - & - & $0 \cdot 16$ & $0 \cdot 281$ & $0 \cdot 118$ & 0.019 \\
\hline Brussels sprouts & \multicolumn{4}{|c|}{ (adjusted $R^{2}=0 \cdot 17$ ) } & \multicolumn{4}{|c|}{ (adjusted $R^{2}=0.19$ ) } \\
\hline Constant & & $3 \cdot 746$ & 0.426 & 0.000 & & $2 \cdot 604$ & 0.660 & 0.000 \\
\hline Age & $0 \cdot 31$ & 0.618 & $0 \cdot 139$ & 0.000 & $0 \cdot 21$ & $0 \cdot 411$ & $0 \cdot 136$ & 0.003 \\
\hline Perceived sourness & -0.24 & -0.021 & 0.006 & 0.001 & -0.17 & -0.014 & 0.006 & 0.015 \\
\hline Perceived umami & $0 \cdot 16$ & 0.013 & 0.006 & 0.021 & - & - & - & - \\
\hline Foods for health & $0 \cdot 16$ & 0.336 & $0 \cdot 146$ & 0.022 & $0 \cdot 19$ & $0 \cdot 401$ & $0 \cdot 143$ & 0.006 \\
\hline Flavour impact & - & - & - & - & 0.23 & 0.018 & 0.005 & 0.001 \\
\hline Information & - & - & - & - & $0 \cdot 14$ & 0.584 & 0.287 & 0.043 \\
\hline Broccolini & \multicolumn{4}{|c|}{ (adjusted $R^{2}=0.30$ ) } & \multicolumn{4}{|c|}{ (adjusted $R^{2}=0.26$ ) } \\
\hline Constant & & $6 \cdot 784$ & 0.234 & 0.000 & & 3.936 & 0.273 & 0.000 \\
\hline Perceived sweetness & $0 \cdot 27$ & 0.019 & 0.004 & 0.000 & $0 \cdot 30$ & 0.026 & 0.006 & 0.000 \\
\hline Perceived sourness & -0.25 & -0.018 & 0.005 & 0.000 & $0 \cdot 21$ & -0.019 & 0.006 & 0.002 \\
\hline Foods for health & $0 \cdot 18$ & 0.268 & 0.091 & 0.004 & 0.24 & 0.432 & 0.115 & 0.000 \\
\hline Perceived bitterness & $-0 \cdot 17$ & -0.010 & 0.004 & 0.015 & - & - & - & - \\
\hline Foods for pleasure & $0 \cdot 13$ & 0.206 & 0.098 & 0.037 & $-0 \cdot 18$ & $0 \cdot 351$ & $0 \cdot 123$ & 0.005 \\
\hline Perceived saltiness & - & - & - & - & $-0 \cdot 15$ & -0.014 & 0.006 & 0.033 \\
\hline
\end{tabular}

no-information groups did not report the specific health (cancer risk reduction) information. A recent Australian qualitative study ${ }^{(36)}$ also reported general but not specific health knowledge (i.e. no recall of disease risk reduction) pertaining to vegetables (and fruit). This could be valuable information for consumers; however, caution is warranted in the light of other findings (below).

Focusing just upon consumption and information, there would appear to be some influence upon liking and intentions to consume (the least liked) Brussels sprouts. The multivariate models, taking into account a greater number of possible influences, confirm that it is possible that information may have some small effects upon the popularity of Brussels sprouts (intentions to consume). Those with generally higher reported vegetable intakes may be more influenced.

There was generally good agreement between consumer perceptions and the trained sensory panel. Hence it would seem that consumers can give valid measures of their perceptions of the basic tastes. This supports previous observations ${ }^{(37)}$ that have found validity of untrained consumers' reports of sensory perceptions.

While it is notable that the most popular Brassica, broccoli, was not perceived to be particularly relatively sweet on average, multivariate analysis found sweet perception as a predictor of broccoli and broccolini liking and intentions to consume. Identifying, changing or highlighting the sweetness of Brassica vegetables (for example, by changing intrinsic sugar content) may be useful in changing acceptance.

Table 6 shows that the independent variables measured explain moderate variance in liking and intentions to consume Brassica vegetables, with a tendency for liking to be better explained. In this respect the liking models support the original rationale of this study, i.e. that sensory perception is associated with liking. Given the wide 
range of behaviours and situations (not measured) that could impact upon intention to consume widely reported in the literature ${ }^{(12,38)}$, it is not surprising that the intention to consume models explain only a low to moderate amount of variance. For theoretical models with a focus on specific variables, these are nevertheless reasonable and expected. The better models, generally predictors of liking, can explain around one standard deviation in the dependent variables. Importantly, many of the predictors are potentially malleable and reflect the rationale of the project.

Sensory perception seems to dominate liking and, while tastes were not perceived to be particularly strong (mean scores were moderate), their importance as predictors is a reflection of the variance across the participants. What influences that variance is unknown but could include experience and learning (exposure and/or conditioning $^{(9)}$ ) and/or genetics ${ }^{(3)}$. The importance of taste supports conclusions drawn from recent survey data $^{(5)}$ that taste drives vegetable (and fruit) consumption and that taste, not health attributes, should be addressed.

Attitudes towards foods for health were relevant in some cases but tended to be minor predictors. Importantly, it is rare ${ }^{(20)}$ for both sensory and attitudinal responses to be included in a single study; hence placing sensory perception in competition with attitudes in the current study is a useful approach. Age and female gender, characteristics that are known to be associated with reported 'healthy' eating ${ }^{(39)}$, were sometimes positive predictors. Notably, age was the strongest positive predictor of the least liked and most bitter vegetable, Brussels sprouts. Age-related taste dysfunction is less common than smell loss and reports of taste impairment are inconsistent; however, bitter sensitivity appears to be the most affected by age $^{(40)}$. In the current study the age range was not wide (18-55 years), due to deliberately excluding older participants who may suffer declines in sensory ability, so this age effect is unlikely to be due to age-related physiological changes. Furthermore, it is unknown if this is an age or cohort effect. It is possible that this is a function of exposure and/or conditioning, i.e. a traditional British vegetable. While only a small number of participants identified with that culture (data not shown), British food culture is apparent among some older Australians.

These consumer data are supported by further investigation of objective measures from chemical analysis of tastes, trained panel sensory descriptive analysis, and health compounds and their activity ${ }^{(27)}$. Those analyses found that the compounds (glucosinolates and phenolics) that contribute to the tastes bitterness and sourness (and acceptance) are the same as those that contribute to the 'healthy' characteristics of Brassica vegetables. Sweetness (intrinsic sugars) was found to offset bitterness and may need to be enhanced to improve acceptability. An alternative or complementary strategy would be to ensure effective exposure and/or conditioning at developmental ages in order to 'teach' acceptance ${ }^{(41)}$.

\section{Limitations}

The novelty and saliency achieved in the current study are known to be necessary for effective information processing; however, participants received only one exposure to cautiously framed, evidence-based information and this may be insufficient to test for effect. Whether repeated exposure to less cautiously framed information would have influenced responses is unknown and may be worth testing. Testing for comprehension and personal relevance may also be important in future studies.

\section{Conclusions}

Among a large group of health-conscious, well-educated Australian adults, the present study found that sensory characteristics, rather than health benefit information, need to be addressed in order to increase the popularity of Brassica vegetables. To a lesser extent attitudes had some influence and are potentially malleable. Only for responses to one vegetable (the least liked Brussels sprouts) did health information have a small influence.

\section{Acknowledgements}

This project was funded by Horticulture Australia Ltd using the vegetable industry levy and matched funds from the Australian Government. There are no conflicts of interest. D.N.C. assisted in the study design, managed the data collection and analysis and drafted the paper. L.M. collected the data, undertook statistical analysis and critically reviewed the manuscript. D.Z. coordinated the larger project, assisted in the study design and critically reviewed the manuscript. C.M.D. initiated the study design and critically reviewed the manuscript. The authors thank Donna Hughes and Raju Krishnamurthy for assistance with data collection and analysis.

\section{References}

1. Jahangir M, Kim HK, Choi YH et al. (2009) Health-affecting compounds in Brassicaceae. Comp Rev Food Sci Food Saf 8, 31-43.

2. Drewnowski A \& Gomez-Carneros C (2000) Bitter taste, phytonutrients, and the consumer: a review. Am J Clin Nutr 72, 1424-1435.

3. Reed DR, Tanaka T \& McDaniel AH (2006) Diverse tastes: genetics of sweet and bitter perception. Physiol Behav 88, 215-226.

4. Tuorila H, Huotilainen A, Lahteenmaki L et al. (2008) Comparison of affective rating scales and their relationship to variables reflecting food consumption. Food Qual Pref 19, 51-61.

5. Schatzer M, Rust P \& Elmadfa I (2010) Fruit and vegetable intake in Austrian adults: intake frequency, serving sizes, reasons for and barriers to consumption, and potential for increasing consumption. Public Health Nutr 13, 480-487.

6. Birch LL (1999) Development of food preferences. Annu Rev Nutr 19, 41-62. 
7. Drewnowski A (2001) The science and complexity of bitter taste. Nutr Rev 59, 163-169.

8. Newcomb RD, McRae J, Ingram J et al. (2010) Genetic variation in taste and odour perception: an emerging science to guide new product development. In Consumer Driven Innovation in Food and Personal Care Products, pp. 571-591 [SR Jaeger and HJH MacFie, editors]. Oxford: Woodhead Publishing Ltd.

9. de Houwer J, Thomas S \& Baeyens F (2001) Associative learning of likes and dislikes: a review of 25 years of research on human evaluative conditioning. Psychol Bull 127, 853-869.

10. Eertmans E, Baeyens F \& van den Bergh O (2001) Food likes and their relative importance in human eating behavior: review and preliminary suggestions for health promotion. Health Educ Res 16, 443-456.

11. Anderson AS, Cox DN, McKellar S et al. (1998) Take Five, a nutrition education intervention to increase fruit and vegetable intakes: impact on attitudes towards dietary change. Br J Nutr 80, 133-140.

12. Cox DN, Anderson AS, Reynolds J et al. (1998) Take Five, a nutrition education intervention to increase fruit and vegetable intakes: impact on consumer choice and nutrient intakes. Br J Nutr 80, 123-131.

13. Lucknow T, Sheehan V, Fitzgerald E et al. (2006) Exposure, health information, flavour masking strategies for improving sensory quality of probiotic juice. Appetite 47, 315-323.

14. Mialon VS, Clark MR, Leppard PI et al. (2002) The effect of dietary fibre information on consumer responses to breads and 'English' muffins: a cross-cultural study. Food Qual Pref 13, 1-12.

15. Sabbe S, Verbeke W, Deliza R et al. (2009) Effect of a health claim and personal characteristics on consumer acceptance of fruit juices with different concentrations of acai (Euterpe oleracea Mart.). Appetite 53, 84-92.

16. Tuorila H, Andersson Å, Martikainen A et al. (1998) Effect of product formula, information and consumer characteristics on the acceptance of a new snack food. Food Qual Pref 9, 313-320.

17. Tuorila H, Meiselman HL, Bell R et al. (1994) Role of sensory and cognitive information in the enhancement of certainty and linking for novel and familiar foods. Appetite 23, 231-246.

18. Wansink B (2003) Overcoming the taste stigma of soy. J Food Sci 68, 2604-2606.

19. Wansink B, van Ittersum K \& Painter JE (2004) How diet and health labels influence taste and satiation. J Food Sci 69, issue 9, S340-S346.

20. van den Heuvel T, van Trijp H, van Woerkum C et al. (2007) Linking product offering to consumer needs; inclusion of credence attributes and the influences of product features. Food Qual Pref 18, 296-304.

21. Willett W (2010) Fruits, vegetables and cancer prevention: turmoil in the produce section. I Nat Cancer Inst 102, $510-511$.

22. The Cancer Council Australia (2007) National Cancer Prevention Policy 2007-09. Camperdown, NSW: The Cancer Council Australia.

23. Aaron JI, Mela DJ \& Evans RE (1994) The influences of attitudes, beliefs and label information on perceptions of reduced-fat spread. Appetite 22, 25-37.
24. Roininen K, Lahteenmaki L \& Tuorila H (1999) Quantification of consumer attitudes to health and hedonic characteristics of foods. Appetite 33, 71-88.

25. Roininen K, Tuorila H, Zandstra EH et al. (2001) Differences in health and taste attitudes and reported behaviour among Finnish, Dutch and British consumers: a cross-national validation of the Health and Taste Attitude Scales (HTAS). Appetite 37, 33-45.

26. Ball K, Crawford D \& Mishra G (2006) Socio-economic inequalities in women's fruit and vegetable intakes: a multilevel study of individual, social and environmental mediators. Public Health Nutr 9, 623-630.

27. Zabaras D, Cox DN, Konczak I et al. (2011) HealthPromoting Vegetables that do not Compromise on Taste. Sydney: Horticulture Australia Limited.

28. Macfie HJ, Bratchell N, Greenhoff K et al. (1989) Designs to balance the effect of order of presentation and first-order carry-over effects in hall tests. J Sens Stud 4, 129-148.

29. Booth M (2000) Assessment of physical activity: an international perspective. Res Q Exerc Sport 72, 2 Suppl., S114-S120.

30. IPAQ Group (2011) International Physical Activity Questionnaire (IPAQ). http://www.ipaq.ki.se (accessed February 2011).

31. Prescott J (2010) Analysis, acceptability \& cognition. In Proceedings of the 4 th European Conference on Sensory and Consumer Research, Vitoria-Gastiez, Spain, 5-8 September 2010. Oxford: Elsevier.

32. Earthy PJ, MacFie HJH \& Hedderley D (1997) Effect of question order on sensory perception and preference in central location trials. J Sens Stud 12, 215-237.

33. Peryam D \& Girardot NF (1952) Advanced taste test method. Food Eng 24, 58-61.

34. Freshlogic (2011) Veginsights: The market - Q1 11, A profile of the three-month period ending 31 March 2011. http://www.pma-anz.com/userfiles/files/Veginsights\%20June\% 202011.pdf (accessed April 2011).

35. Bialkova S \& van Trijp HCM (2011) An efficient methodology for assessing attention to and effect of nutrition information displayed front-of-pack. Food Qual Pref 22, 592-601.

36. Carter OBJ, Pollard CM, Atkins JFP et al. (2011) 'We're not told why - we're just told': qualitative reflections about the Western Australian Go for $2 \& 5^{\circledR}$ fruit and vegetable campaign. Public Health Nutr 14, 982-988.

37. Worch T, Lê S \& Punter P (2010) How reliable are the consumers? Comparison of sensory profiles from consumers and experts. Food Qual Pref 21, 309-318.

38. Pollard C, Miller M, Woodman RJ et al. (2009) Changes in knowledge, beliefs, and behaviors related to fruit and vegetable consumption among western Australian adults from 1995 to 2004. Am J Public Health 99, 355-361.

39. Wardle J, Haase AM, Steptoe A et al. (2004) Gender differences in food choice: the contribution of health beliefs and dieting. Ann Behav Med 27, 107-116.

40. Nordin S (2010) Sensory perception of food and ageing. In Food for the Ageing Population, pp. 73-94 [M Raats, L de Groot and W van Staveren, editors]. Oxford: Woodhead Publishing Ltd.

41. Corsini N, Slater A, Harrison A et al. (2011) Rewards can be used effectively with repeated taste exposure to increase liking of vegetables in 4-6 year-old children. Public Health Nutr (Epublication ahead of print version). 